\title{
HISTÓRIAS DE PACIENTES COM CÂNCER DE BOCA E PRÁTICAS DE FUMO EM ÁREAS RURAIS DO NORDESTE BRASILEIRO
}

\author{
Stories of patients with cancer of the mouth and practices \\ of smoke in rural areas of northeastern Brazil \\ Historias de pacientes con cáncer de boca y prácticas de \\ humo en las zonas rurales del noreste de Brasil
}

Roxane de Alencar Irineu ${ }^{1}$

Andrea Caprara

\begin{abstract}
Resumo
Este artigo tem como eixo central compreender as práticas do fumar através das narrativas de pacientes que tiveram câncer de boca. Utilizamos a história de vida como recurso metodológico para este fim, por ser o testemunho da experiência vivida pelo sujeito. Analisaremos as narrativas de cinco sujeitos escolhidos entre um universo de 30 pacientes portadores de câncer de boca, com idade superior a 50 anos, moradores da zona rural, que foram atendidos em um hospital de Fortaleza. 0 hábito de fumar teve início muito cedo em suas vidas, pela busca do prazer proporcionado pelo tabaco, influenciados por vezes pela própria família, pela cultura local, pela imagem lisonjeira sugerida pela publicidade, ou ainda para aliviar a dor e a fome. A doença surge, e com ela o sofrimento, o estigma, a cirurgia, as seqüelas, as mudanças físicas. Trabalhadores da roça, sofridos, com fome, excluídos da sociedade, essa é a sua imagem.
\end{abstract}

Palavras-chave: Neoplasias Bucais. Tabaco. Narração.

\begin{abstract}
This article tries to understand the practice of smoking through the narratives of patients who had mouth cancer. The beginning of the practice of smoking, the relationship between the pleasure of smoking and the need to stop, the suffering caused by cancer, are issues that guided our research. We utilized the history of life as a resource methodology for this purpose, being it the testimony of the subjects' experience, linking the past, present and future of every single patient. In this article we analyze in particular the narratives of five subjects chosen from a universe of thirty patients with mouth cancer, aged over 50 years, residents of the rural area that were attended in a Hospital of Fortaleza, Brazil. The habit of smoking began very early in their lives, by the pursuit of pleasure offered by tobacco, sometimes influenced by the family, the local culture, the images by advertising or to relieve pain and hunger. The disease comes, and with it the suffering of diagnosis, the stigma, the surgery, the sequels, the physical changes and stop smoking. Employees of the country, suffered with hunger, excluded from society, this is the image of them. The pleasure was transformed into pain.
\end{abstract}

\section{Resumen}

Este artículo tiene, como objetivo, entender las prácticas de fumar a través de las narrativas de pacientes con cáncer de boca. Utilizamos las historias de vida como metodología de investigación. Analizaremos las historias de cinco pacientes escogidos en un universo de treinta sujetos con cáncer de boca, con más de 50 años de edad, residentes de la zona rural que fueron tratados en un hospital de Fortaleza. El hábito de fumar se inició muy temprano en su vida, por el placer que ofrece el tabaco, as veces por la influencia de la familia, de la cultura local, de la imagen sugerida por la publicidad o para aliviar el dolor y el hambre. La enfermedad Ilega, y con ella el sufrimiento, el estigma, la cirugía, las secuelas, los cambios físicos. Por la mayoría son campesinos que sufren con el hambre, excluidos de la sociedad. 


\section{INTRODUÇÃO}

Este artigo visa compreender as práticas do fumar de pacientes submetidos a tratamento para o câncer de boca e que vivem em áreas rurais do nordeste brasileiro. 0 indivíduo que se submete a este tipo de tratamento sofre, na sua grande maioria, mutilações com repercussões importantes na sua vida pessoal, profissional e social. As transfigurações na face não são raras, por isso perde-se o esquema corporal e sua identidade social fica comprometida. Cria-se um estigma, pois este sujeito passa de um ser "normal" para um ser estigmatizado, aquele que foge dos padrões".

Acreditamos que o estigma gerado nessas pessoas, na maioria das vezes, é ocasionado pela dificuldade no falar e no comer e, por vezes, pela deformidade física na face (visível). 0 contato social, por sua vez, já não é mais prazeroso, o medo da não-aceitação parece fazer-se constante. Falar com alguém torna-se motivo de receio e ansiedade, assim como alimentarse é transformado num momento de dor e imprevistos, uma vez que esses pacientes não têm mais as estruturas orais íntegras para a realização destas funções. A deglutição pode vir acompanhada de engasgos, de dor, de movimentos compensatórios que chamam a atenção de outros. A fala aparece imprecisa, por vezes ininteligível, com sons imperfeitos e cheios de ruídos.

Essas dificuldades tornam-se ainda maiores por ser este estigma adquirido em uma fase avançada da vida, em que 0 mesmo já ouviu muito sobre normais e estigmatizados e agora é obrigado a considerar a si próprio como diferente.

Na busca por literatura, pudemos constatar trabalhos cientificos sobre a qualidade de vida de pacientes com câncer de boca realizados prevalentemente através de estudos quantitativos ${ }^{2,3,4,5}$. No entanto, pouco foi investigado, através de abordagens de tipo qualitativo, a respeito da experiência de sujeitos submetidos ao tratamento do câncer de boca, assim como sobre as histórias de vida desses pacientes.

Para abordar essas temáticas, apresentaremos os resultados desta pesquisa realizada em um hospital de Fortaleza, estrutura de referência para o tratamento do câncer de cabeça e pescoço no estado do Ceará. Analisaremos em particular as narrativas de cinco sujeitos escolhidos entre um universo de 30 pacientes portadores de câncer de boca, com idade superior a 50 anos.

\section{MÉTODOS}

A abordagem escolhida para este estudo é de natureza qualitativa, seguindo a metodologia da história de vida ${ }^{6,7,8}$. A análise dos textos foi desenvolvida através de uma abordagem inspirada na hermenêutica de P. Ricoeur assim como apresentada por Geanellos ${ }^{9}$.

A metodologia de história de vida foi adotada por ser um processo de compreensão de experiências e reconstrução de vivências ${ }^{13,14}$.

0 relato de vida é contado por um personagem e gira em torno deste. No entanto, o que existe de individual e único numa pessoa é excedido, em todos os seus aspectos, por uma infinidade de influências culturais que nela se cruzam ${ }^{11}$. Em vista disso, a história de vida de alguém se encontra sob duas perspectivas: a do indivíduo com sua herança biológica e suas peculiaridades e a de sua sociedade com sua organização e valores específicos, captando o que sucede na tessitura da vida individual com o social. Tivemos, portanto, o objetivo através da história de vida não só de ouvir os relatos e sim saber como os eventos foram vividos em todo o seu processo e como o câncer de boca foi modificando a vida dessas pessoas.

0 hospital estudado está entre os que realizam o maior número de cirurgias nessa área, coexistindo com um centro de estudos avançados em oncologia.

Analisamos o relato de dois sujeitos do sexo masculino e três do sexo feminino nas idades compreendidas entre 56 e 80 anos. Embora considerássemos que 0 estudo, voltado para a análise da vivência do ser, não sofre necessariamente interferência nessas duas variáveis, e de não ser nosso objetivo fazer distinções entre os dados referentes a sexo e faixa etária, o indicativo de idades aproximadas entre os sujeitos diminui a distância entre as realidades.

0 estágio clínico do tumor não foi levado em conta, por interessarem apenas, para nós, as seqüelas por ele deixadas. A combinação de diversas formas de tratamento, como cirurgias, radioterapia e quimioterapia, para o tratamento do câncer de cabeça e pescoço no estado do Ceará, aconteceu com freqüência nos sujeitos, visto que é preconizada a associação de duas ou mais técnicas no tratamento desse câncer.

Todos os sujeitos que participaram deste estudo foram selecionados a partir de visitas realizadas no hospital no serviço de oncologia. Dentre os critérios de seleção utilizados, vale mencionar a possibilidade de o sujeito comunicar-se oralmente. Mesmo tendo realizado, por vezes, grandes ressecções de estruturas da boca, foi imprescindível selecionar apenas aqueles com condição de fala. Quase todos os sujeitos apresentavam importantes alteraç̃oes no processo de alimentação e na fala, o que muito dificultou as entrevistas, especialmente 0 momento das transcrições, quando já não fazíamos mais uso do recurso de leitura labial. Portanto, a estratégia utilizada por nós foi a de realizar as transcrições imediatamente após os encontros, quando ainda podíamos fazer uso da nossa memória.

As entrevistas aconteceram em uma sala do ambulatório do hospital, reservada apenas para esse fim, assim como na residência do próprio paciente, quando este não podia comparecer ao hospital ou quando achávamos pertinente viabilizar um momento de maior cumplicidade para, desta forma, compreender mais profundamente o paciente e sua dinâmica familiar.

0 projeto de pesquisa foi apresentado e aprovado pelo Comitê de Ética da Universidade Estadual do Ceará, na data de 10 de agosto de 2005, sob o número $05173694-2$, e os nomes dos sujeitos, aqui apresentados, são todos fictícios. 


\section{RESULTADOS}

Neste artigo analisamos em particular as narrativas de cinco pessoas escolhidas entre um universo de 30 pacientes portadores de câncer de boca; todos eles têm idade superior a 50 anos. Estamos interessados na capacidade de reflexão, na sensibilidade dos sujeitos, o que eles sentem e percebem a partir do relato da história de vida. Dentre as cirurgias nesta área delimitamos aquelas com seqüelas, já confirmadas, na comunicação e/ou deglutição, dentre elas as cirurgias de lábios, língua, assoalho da boca e mandíbula.

Os cinco sujeitos que fizeram parte do nosso estudo apresentam histórias únicas e singulares que se diferenciam desde o diagnóstico do câncer, estadiamento da lesão, seqüelas apresentadas, até a reação diante da doença. 0 que temos de comum entre elas é a localização do câncer, todos na boca, o nível sócio-econômico baixo, o que levava a utilizarem 0 sistema público de saúde, e a relação da doença com o hábito de fumar; além de serem todos provenientes de zonas rurais do nordeste brasileiro. Mostraremos, nesse breve histórico, o que caracterizou a história de cada um deles em especial, e tentaremos entrecruzar as recorrências.

\section{Breve descrição das cinco histórias de vida}

Mariana: "O povo todo da roça fuma"

Mariana tinha uma lesão extensa que comprometia várias estruturas, além da idade bastante avançada, 80 anos. Fumava, em média, 10 cachimbos e também alguns cigarros por dia, tendo iniciado o hábito de fumar aos 10 anos de idade porque sua mãe solicitava que os filhos acendessem seu cachimbo. Fala do fumo com um prazer ainda grande: "O povo todo da roça fuma...fumar é muuuuito bom", e refere não saber da relação dele com a neoplasia. Fumou até a data do diagnóstico da primeira lesão cancerígena na boca, em 2001.

Mariana nasceu no município de Quixeré no ano de 1924, é viúva, teve oito irmãos, cinco homens e três mulheres, era a caçula entre eles. Seus pais eram agricultores e toda a família participava do trabalho na terra. Quando completou 8 anos de idade foi ajudar na roça, plantando feijão e mandioca, e, portanto, nunca teve muito tempo para brincar. Sempre morou na sua terra natal, veio para Fortaleza quando da necessidade de realizar sua primeira cirurgia, não sendo mais possível ficar longe do apoio médico. Atualmente, habita com a nora, o único filho e netos. Realizou duas cirurgias: a primeira foi no lábio inferior e depois fez ressecção de faringe, palato mole com extensão para amígdala, área retromolar e base de língua.

\section{Elizabete: "Quando fumava eu me sentia absoluta"}

Elizabete realizou cirurgia, em fevereiro de 2001. Nasceu no município de Russas, tem 57 anos, três filhos, dois são adotados (colocaram na porta da sua casa), e o mais novo, de 16 anos, é filho legítimo. Sobrevive e sustenta dois filhos que ainda moram com ela, com a pensão deixada pelo marido falecido, de 320 reais.

Elizabete mostra em seu discurso uma história de vida marcada pelo sofrimento e depressão. A primeira grande ruptura em sua vida aconteceu com a separação dos pais, quando, na ocasião, além de ficar sem o pai, a família começou a passar dificuldades financeiras. Todos os filhos tiveram que ajudar no sustento da família, e Elizabete, aos 11 anos, foi trabalhar como doméstica porque, segundo ela, não tinha o que comer. Houve uma separação de toda família, e ela relata que, a partir de então, só problemas aconteceram em sua vida. Carência, insegurança e medo começaram a permear seu consciente; Elizabete começou a fumar: "Quando fumava eu me sentia absoluta."

Casou-se com um homem mais velho que a acolheu como filha. Elizabete nunca cultivou, em si mesma, a possibilidade de se manter sobre as próprias pernas, se sustentando a partir daí na força do marido e, após seu falecimento, transferiu toda essa dependência à irmã. Ela alega um completo desamparo e submissão. A morte do marido aparece como segunda grande ruptura em sua vida: ela perde o "chão", dependia dele para tudo. Começou a sentir solidão, e seu sofrimento foi arrebatador.

Logo em seguida veio a doença, o câncer de boca que lhe trouxe mais uma ruptura, nem tanto pelo diagnóstico em si, mas pela seqüela deixada pela cirurgia que mudou totalmente a vida de Elizabete. Ela ficou em casa deitada numa rede chorando durante meses, até que um dia resolveu se levantar, conseguiu sair de casa e dizer: "eu não posso viver assim". Ela saiu do processo depressivo, porém continua numa relação difícil com as seqüelas.

\section{Figura 1. Perdas e consequiencias emocionais na vida do sujeito}

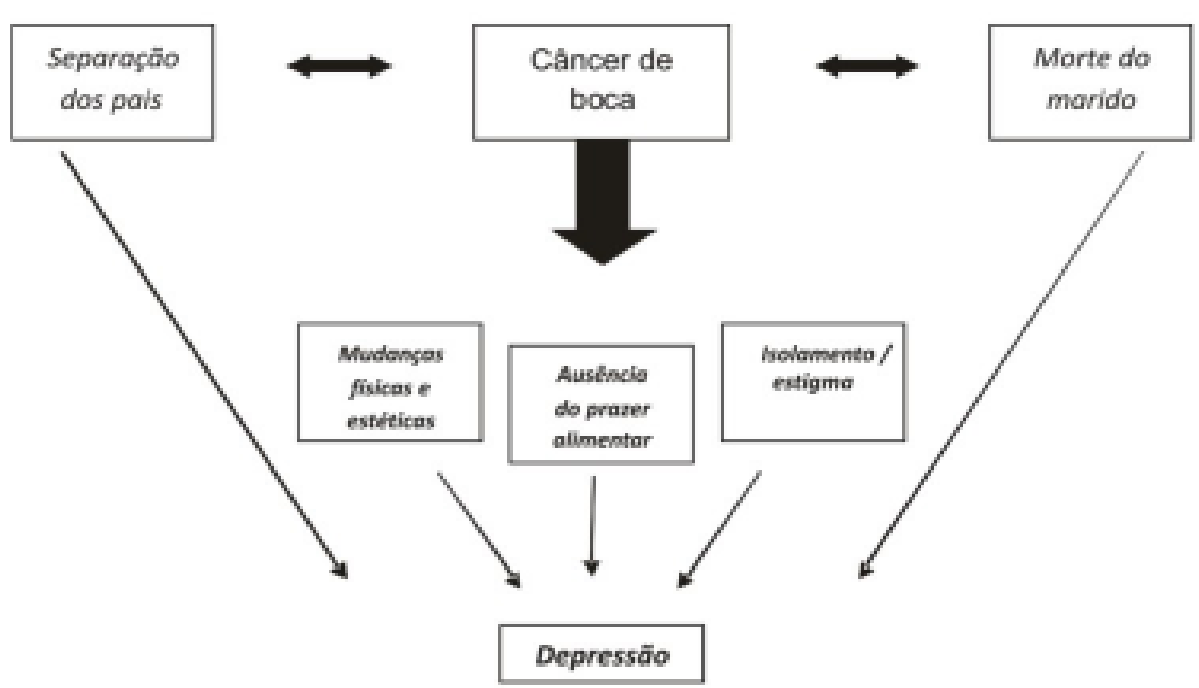


Na Figura 1 colocamos, em um mesmo nível, as perdas acumuladas e, em seguida, as conseqüências dessas perdas. $A$ separação dos pais, a morte do marido e o câncer de boca foram diretamente responsáveis pela depressão e, acumulados com a cirurgia, tiveram como conseqüência mudanças físicas e estéticas, ausência do prazer alimentar e isolamento. No centro das perdas, encontra-se o câncer de boca, por estar, no momento, em evidência na sua vida.

\section{Josué: "Sempre gostei muito de fumar e beber"}

Nasceu em Caucaia, tem 56 anos, é separado, tem três filhas. É o primeiro filho de uma prole de 11. Destes, sete são mulheres e quatro homens, apenas um deles é falecido. Teve câncer, amputou as duas pernas e ficou por seis anos convalescendo em uma cama. Seu pai faleceu aos 92 anos de idade com pneumonia, sua mãe ainda é viva, lúcida e dinâmica, tendo hoje 79 anos de idade: "Meu pai era muito trabalhador... plantava milho, feijão, mandioca... eu que ia vender no centro... eu sempre trabalhei".

Josué teve um câncer em estádio avançado, tendo que realizar uma cirurgia que consistiu na retirada de toda a língua (glossectomia total). Esteve, durante seis meses, freqüentando um posto de saúde próximo à sua casa, sem conseguir obter 0 diagnóstico correto de sua doença, tomando benzetacil de dois em dois meses.

Sempre gostou de fumar e beber, fumava cigarro comum e também o "pé-duro", que consiste na utilização de fumo de corda enrolado em palha: "Quando não tinha o cigarro, eu ficava doidinho".

Quando descober to o câncer, as seqüelas, evidentemente, não foram simples. Porém no seu discurso caracteriza-se a negação: Josué prefere dizer que não sente nada, não mudou nada em sua vida, as funções orais estão normais, apesar de sua fala ser quase ininteligível e não conseguir engolir nem a saliva durante nossa conversação. Ele talvez acredite que a única maneira de ficar seguro é tornando-se tão forte e invulnerável, tão independente e sem emoção que nada, nem ninguém, pode atingi-lo. Cultiva uma dureza que não é mais real que a doçura desamparada da pessoa submissa, mantém um orgulho óbvio. Estar doente é estar frágil, não é possível ser frágil para Josué.

No centro da figura, o sujeito de negação. Josué se nega a ficar nessa relação de assunção com esses fatores:

A minha infância foi boa... a dificuldade era que, às vezes, tinha o feijão mas não tinha a carne... tinha o arroz e não tinha feijão. Mas toda vida tinha o que comer.

\section{Francio: "no mar é bom um cigarrinho"}

Francio é considerado pela família um exemplo de homem, bom pai, bom marido, um homem bom. Ele é casado, pai de uma filha de 21 anos, avô de um bebê de seis meses. Reside em Aquiraz, com sua esposa, filha e neta. Tem 65 anos, fumou de 18 até os 61 anos de idade. 0 início da prática do fumo se deu no mar, alem de trabalhar na roça, ele começou a pescar, e, segundo ele, a solidão sugeriu uma companhia. 0 cigarro aparece, então, como um companheiro: “...no mar é bom um cigarrinho." "Eu fumava três carteiras por dia. No normal era uma, mas, bebendo, o caba fica de vez em quando acendendo um." Parou de fumar dois anos antes de aparecer os sintomas do câncer, utilizando um filtro que tira o gosto do cigarro e portanto facilita a eliminação do hábito (segundo o mesmo).

Procurou o Instituto de Prevenção do Câncer por apresentar um vermelhão na boca que progrediu com muita dor. Foi diagnosticado carcinoma espinocelular de assoalho da boca à direita; realizou cirurgia em agosto de 2003 (pelveglossectomia e esvaziamento cervical supra-omoióideo à direita).

Maria: "tava com uma raiva medonha, tocava fogo no cigarro e pronto".

Maria tem 69 anos de idade, nasceu em 1935, na cidade de Senador Pompeu - CE. Tem 11 filhos, quatro homens e sete mulheres, sendo um deles adotivo, a filha mais nova que foi para o seu poder com 24 horas de nascida. Tem netos e bisnetos, é uma pessoa muito querida na família e é considerada por todos eles um "tesouro". Mora, ainda hoje, na cidade em que nasceu, na companhia do seu marido e da filha mais nova. Apresentou um câncer de língua do tipo carcinoma espinocelular, fez uma glossectomia parcial (retirada de parte da língua) em 2004 e apresentou metástase linfonodal cervical, realizando então uma segunda cirurgia em junho de 2005. A porção retirada da língua foi relativamente pequena, e, por isso, Maria não se encontra com seqüelas muito importantes das funções orais.

Maria deixa em seu discurso a marca da exclusão social vivida por ela, mais do que seqüelas deixadas pelo câncer. Teve uma vida dura, sofrida, passou fome. Seu pai ficou doente aos 26 anos de idade, sem nenhum tipo de assistência médica, morreu quatro anos depois por não ter recurso para pagar sua cirurgia. Seu acesso aos serviços de saúde foi negado. A morte do pai parece ter sido um marco em sua vida, talvez um fator de resiliência para a condição atual. Após a morte de seu pai, que os deixou ainda mais pobres, Maria "arregaçou as mangas" e tratou de enfrentar a dor. Ela, a filha mais velha e seu único irmão. Ela com 7 anos, ele com um pouco mais, aprenderam com um tio a trabalhar na terra e, depois de três anos, estavam plantando no pedaço de terra deixado pelo pai e, desta forma, sustentando a família. A vida dura na infância lhe faz forte. "Nesse rojão batalhamo a vida e se criamo tudim...".

Suas dificuldades continuaram: "Eu casei pra ver se tinha descanso, mas não tive". Maria viu sua filha mais velha quase morrer de fome, enquanto trabalhava na roça com seu pai, limpando o mato com uma enxada. 0 pai, por não ter o alimento, botou fumo na boca da criança. Maria passou, então, uma época de grande exclusão social, de pobreza e dor.

Veio a doença, que the trouxe o medo do desconhecido. A negação aparece em sua fala quando chama o câncer de "carocinho" e acredita quando sua filha diz que "ele não é dos que vocês tão pensando". Melhor não saber (?). "Aquela doença feia!" Eu não sou merecedora disso, eu fui tão boa, tão batalhadora, criei meus irmãos, meus filhos, foi tanto rojão na minha vida... não, eu não. 
Quadro 1: Caracterização dos cinco sujeitos entrevistados

\begin{tabular}{|c|c|c|c|c|c|c|c|c|}
\hline Sujeito & Idade & $\begin{array}{l}\text { Est. } \\
\text { Civil }\end{array}$ & Sexo & Origem & Profissão & Diagnóstico & $\begin{array}{l}\text { Hipótese } \\
\text { etioboica }\end{array}$ & Girurgia \\
\hline Mariana & 80 & Víva & Fem. & Quikesé & Agricutora & $\begin{array}{l}\text { Carcinoma } \\
\text { delabio + caroinoma } \\
\text { de palato mole, } \\
\text { amigdala, base da } \\
\text { língua }\end{array}$ & $\begin{array}{l}\text { Cachimboe } \\
\text { cigarro }\end{array}$ & $\begin{array}{l}1^{2} \text { ressecçāo de bábio } \\
\text { inferior } \\
2^{4} \text { ressecçào de } \\
\text { faringe, palato mole, } \\
\text { com extensão para } \\
\text { amigdala, área } \\
\text { retromolar e base da } \\
\text { lin qua }\end{array}$ \\
\hline Elizabete & 57 & Vüva & Fem. & Russas & Dona de casa & $\begin{array}{l}\text { Carcinoma de } \\
\text { amigdala e base da } \\
\text { linaua }\end{array}$ & Gigarro & Ressecção de amigdala \\
\hline Josué & 56 & Separa-do & Masc. & Caucaía & $\begin{array}{l}\text { Pedreiro/ } \\
\text { agricultor }\end{array}$ & $\begin{array}{l}\text { Carcinoma } \\
\text { espinocelular } \\
\text { avançado de lingua }\end{array}$ & $\begin{array}{l}\text { Fumo pé-duro } \\
\text { e adcóol }\end{array}$ & $\begin{array}{l}\text { Glossectoma } \\
\text { total + } \\
\text { esvaziamento } \\
\text { cervical }\end{array}$ \\
\hline Francio & 60 & Casado & Masc. & Aquiraz & $\begin{array}{l}\text { Agricutor/ } \\
\text { pescador/ } \\
\text { comerian- } \\
\text { te }\end{array}$ & $\begin{array}{l}\text { Carcinoma } \\
\text { espinocelular de } \\
\text { lingua e assoalho da } \\
\text { boa }\end{array}$ & Cigarro e alcóol & $\begin{array}{l}\text { Pelveglossectomia + } \\
\text { esvaziamento cervical } \\
\text { supra-omoióideo }\end{array}$ \\
\hline Maria & 69 & Casada & Fem. & $\begin{array}{l}\text { Senador } \\
\text { Pompeu }\end{array}$ & Agricutora & $\begin{array}{l}\text { Carcinoma } \\
\text { espinocelular de } \\
\text { lingua }+ \text { metástase } \\
\text { linfonodal }\end{array}$ & Fumo pé-duro & $\begin{array}{l}\text { Glossectoma parcial + } \\
\text { esvazamento cervical }\end{array}$ \\
\hline
\end{tabular}

Podemos observar, no Quadro 1, que todos os sujeitos desta pesquisa apresentavam idade superior aos 50 anos. 0 câncer de boca é um evento raro antes dos 40 anos de idade; sua incidência aumenta a partir dos 55/60 anos de idade. Todos os sujeitos apresentavam carcinoma do tipo espinocelular, e em todos os casos a língua foi acometida, isoladamente ou associada a outras estruturas da boca.

0 hábito de fumar foi constatado em todos os sujeitos. Dentre as formas de uso, observa-se o cigarro pé-duro (ou de palha), cigarro comum, cigarro de rolo e cachimbo. 0 fumo foi introduzido precocemente na vida deles, muitas vezes estimulado pelos pais, quase todos também fumantes.

\section{O sentido do fumar}

Um raro prazer!

Como todos os entrevistados eram fumantes, não é de se espantar que apareça, em suas falas, uma grande temática de análise, o sentido do fumar. 0 que fica claro nas histórias dos sujeitos desta pesquisa é que para eles a lembrança do fumo é algo bom e está normalmente associado ao prazer. Evidenciase, no entanto, um paradoxo proporcionado pelo prazer do ato de fumar a despeito da dor e do desconforto mórbido provocado pelo câncer. Observemos no Quadro 2 alguns dos depoimentos das pessoas entrevistadas.

Quadro 2: Relação entre o prazer de fumar e a necessidade de parar.

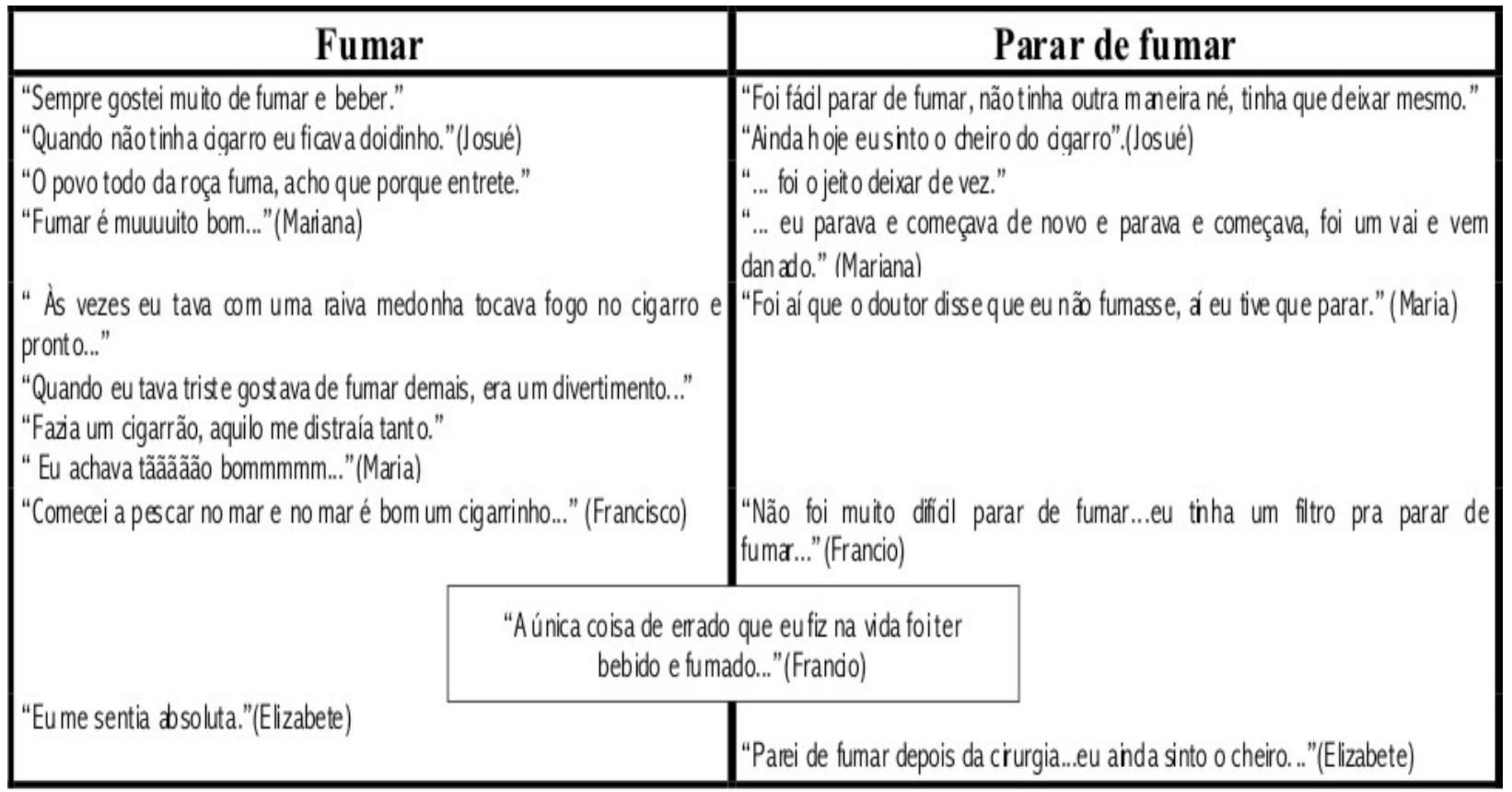


Após ouvir esses depoimentos fica mais claro compreender, mesmo enquanto não fumantes, os trechos das falas dos sujeitos, quando verbalizam o prazer de fumar, prazer este que não desaparece mesmo com a doença. Apesar de ter se tornado passado, o prazer vence a temporalidade e se mantém: "Fumar é muito bom" (Mariana); "...no mar é bom um cigarrinho" (Francio). Apesar de no momento não fumarem mais, o câncer não fez com que essas pessoas achassem ruim fumar. Existe uma manutenção dessa subjetividade anterior, do gostar, do prazer. 0 passado duradouro é marcado pelo uso do pretérito imperfeito, uma coisa é dizer eu fumei e outra é dizer eu fumava. 0 pretérito perfeito não marca durabilidade, é uma ação acabada, já o pretérito imperfeito é uma ação durável, ela também acabou, mas teve uma durabilidade maior. E é aí que o pretérito imperfeito se encontra com o presente. Nesse momento o tempo deixa de ser quando e passa a ser onde: ficava, tocava, tinha, começava...

Notamos que o hábito de fumar parece estar associado a um entretenimento, um divertimento, uma alegria que, por vezes, faz o indivíduo esquecer problemas e sair do tédio. Maria mostra, em seu discurso, ser uma grande entusiasta do fumo. Para ela o fumo fazia esquecer qualquer tristeza ou raiva: “...tocava fogo e pronto...". Ela "não ficava quebrando a cabeça com nada não..." 0 cigarro, em sua vida, foi um companheiro, um remédio para as dores da vida, um alento para sua alma. Mesmo com toda a dificuldade financeira vivida por Maria e sua família, nunca faltou dinheiro para o fumo. Ela e seu marido compravam o fumo por quilo na feira: "era eu e ele e não dava pro mês não". 0 prazer de fumar era tamanho que por vezes até faltava dinheiro para a comida, mas o fumo era uma constante.

No contraponto a todas as falas descritas no quadro, surge Francio com uma pista de culpabilização. “... é bom um cigarrinho..." mas é errado, "a única coisa de errado que eu fiz na vida foi ter bebido e fumado, outra coisa não existiu". Sua fala se posiciona naquela tensão entre o prazer de fumar e 0 pecado. E essa conotação de ter que pagar pelo erro tem um fundamento religioso forte. 0 prazer tem uma relação com 0 pecado. 0 cigarro é um prazer para quem fuma, um alívio, um consolo, uma companhia, mas ao mesmo tempo é um opressor porque escraviza. "...eu ficava doidinho quando não tinha cigarro (Josué)." Ele é o prazer que oprime, o indivíduo passa a ser do cigarro, e não o cigarro dele. Chega um momento em que o vício domina. Foi perguntado aos sujeitos como se dera o processo do começar a fumar:

Quadro 3: Início da prática do fumo dos sujeitos participantes deste estudo.

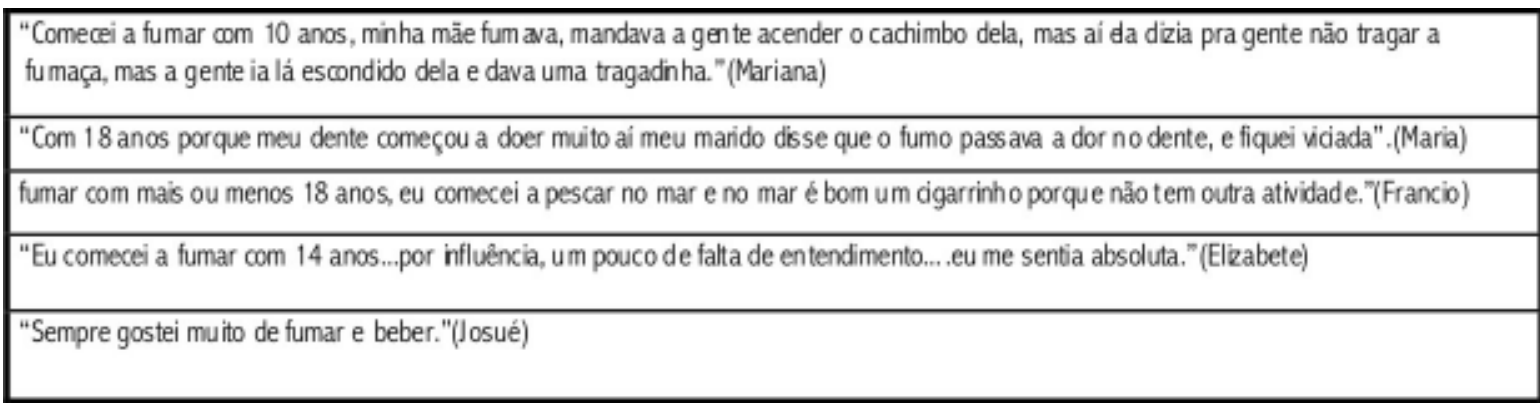

São cinco histórias que mostram o hábito de fumar ainda aceso em suas memórias, hábito este que teve início muito cedo em suas vidas. Muitos, influenciados pela própria família, pela cultura local e, com certeza, também pelo gigantesco trabalho da mídia, outros pela dor e pela fome.

Elizabete começou a fumar com 14 anos, no final da década de 1950. Naquela época, para uma mulher de 14 anos, fumar era uma ousadia tremenda, uma espécie de auto-afirmação, mas ela não se preocupava se fumar era bonito ou feio para uma mulher. Ela simplesmente se sentia absoluta. E, portanto, para Elizabete fumar é bom, sempre foi bom, ela continua sentindo o cheiro do cigarro, assim como Josué: "eu ainda sinto o cheiro".

A pesca, no mar, na história de Francio, pode ter uma conotação de solidão, e o cigarro, de um companheiro. Ele começou a fumar porque ia pescar no mar e não tinha outra atividade. 0 momento da espera, a expectativa proporcionava reflexões sobre a própria vida e a necessidade de companhia.

Já Maria começou a fumar porque seu marido disse que passaria suas dores de dente e, mais adiante, continuou fumando pelo prazer e para vencer a fome. Sua história é o reflexo da exclusão social. Sua família sempre esteve fora do sistema, sem direito à saúde, pobres, esquecidos no mundo, doentes, sem ninguém para olhar por eles. 0 fumo passa a ser seu aliado, um consolador, uma espécie de bálsamo para a vida, como na história de Maria, que é uma história emblemática da pobreza e segregação social.
Maria após casar viveu uma época de grande pobreza, viu a filha mais velha: "dar agonia num cabo de uma enxada de fome", e ela, que não tinha mais o alimento, conta que "ele (o marido) botou na boca dela um pouco de fumo". Refere que 0 marido chegou em casa com a filha nos braços desacordada, e o único alimento que conseguiram para oferecer a filha foi angu de milho. "Eu me tremi todinha, mole, mandei moer, fiz um angu de milho, foi o almoço e a janta pra eles. Angu de milho só com sal". A fome parece ter feito parte da história de vida de Maria. Essa suposição fica clara também quando ela expõe que, ao ir para a roça com o marido realizar seu trabalho diário, seu ganha-pão, passava o dia todo só à base de fumo e café: "Pra mim tendo fumo e café tava bom. A gente passava o dia todim na roça só com fumo e café". Portanto a exclusão social na vida de Maria, causada pela pobreza, caracterizavase, em especial, pela fome. A fome, por sua vez, levava à busca de um alívio, o fumar. Como visto no início, a grande prevalência de câncer de boca ocorre em indivíduos de baixa renda. Além de toda dificuldade exposta, Maria passa a ter sua vida girando, agora, em torno do câncer.

Durante décadas, as pessoas foram induzidas a não pensarem no tabaco como uma substância perigosa para a saúde e indutora de dependência. A imagem era desejável ${ }^{11}$, tanto que os sujeitos nem sempre relacionam seu estado com o fumo, como no Quadro 4. 
Quadro 4: A percepção da relação entre o fumo e o câncer de boca.

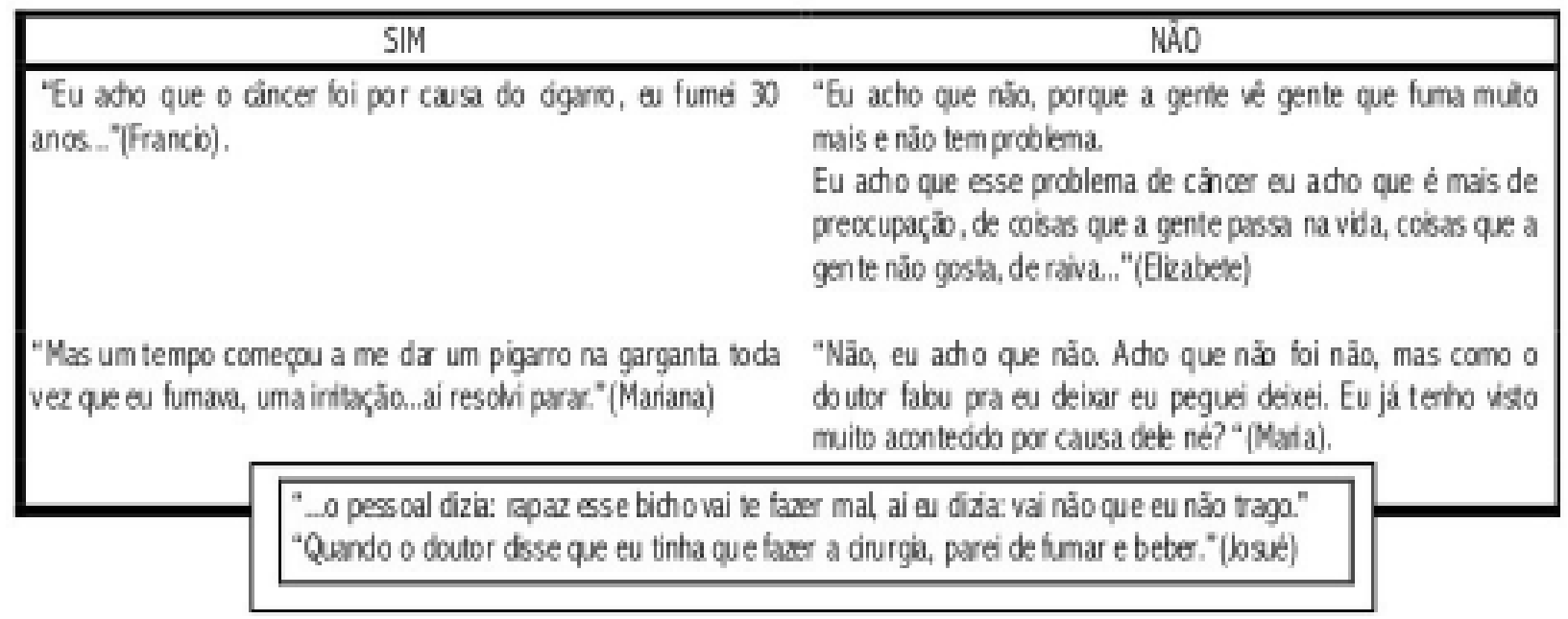

Não fica claro, após análise do Quadro 4, a consciência dos sujeitos em relação à associação do fumo com o câncer de boca. Muitos deles relataram não saber que o fumo poderia ter sido o causador da sua patologia. No entanto, muitas vezes, é comum a ambigüidade no relato, por exemplo: Maria diz que não, referindo-se ao fato de não achar que o fumo era a causa da sua patologia, porém logo em seguida ela diz: "tenho visto muito acontecido por aí e o povo diz que muito é por causa dele". Essa ambigüidade sugere uma tentativa de negar sua culpa na origem, na gênese da sua doença, o povo é que diz, ela não sabe.

Elizabete vai além, tenta criar uma teoria sobre a etiologia de sua doença, traz a sua história de vida, o sofrimento vivenciado por ela, como a causa de todo o problema: "Eu acho que esse problema de câncer é mais de preocupação, de coisas que a gente passa na vida, coisas que a gente não gosta, de raiva." Ela nega a relação do seu câncer com o hábito de fumar. Seu discurso é repleto de palavras como: dificuldade, tristeza, problemas, solidão, dependência e desgosto. Essas palavras carregam um peso, a vida de Elizabete não é leve, não aparece em seu discurso a palavra felicidade, contentamento. Ela

\section{CONSIDERAÇÕES FINAIS}

Através das narrativas dos casos estudados pudemos observar que o hábito de fumar fez parte de suas histórias de vida de forma significativa, marcando épocas, momentos, perdas e ganhos. 0 começo da prática esteve sempre relacionada à busca por um maior conforto, uma companhia que faltava; uma dor de dente que não passava; a vontade de ousar e transgredir regras; a fome, comum em algumas histórias durante horas de trabalho duro na roça; a continuação de hábitos familiares e sociais, para não fugir as regras; além da busca por divertimento e entretenimento. No entanto, num dado momento da vida desses sujeitos, o cigarro começou a mostrar-se prejudicial, uma irritação na garganta, um caroço no pescoço, dores, inflamações. 0 câncer surge, e com ele a ruptura em suas histórias. A cirurgia, como recurso terapêutico, trouxe para os pacientes desta pesquisa um sentimento paradoxal: de um lado a possibilidade da cura, do outro a realidade das seqüelas nas funções orais deixadas em decorrência da mesma. Mudanças físicas e estéticas, dificuldades para falar e comer, alterações demonstra uma forma de significar a própria vida como vítima, ela parece ser a vítima da sua vida; mais uma vez a vida lhe prega uma peça, a doença aparece, não foi ela a mentora, ela jamais faria isso com ela própria.

Josué acreditava que o fato de não tragar a fumaça do cigarro nada Ihe aconteceria; mesmo os amigos alertando do perigo do fumo pé-duro, ele insistiu em continuar fumando, negando a relação do seu hábito com um provável problema de saúde: “... eu fumava aquele fumo pé-duro, aí o pessoal dizia assim: rapaz esse bicho vai te fazer mal, aí eu dizia vai não que eu não trago." Francio, no entanto, conhecia a relação de causa e efeito do cigarro com o câncer apresentado por ele, apesar de analfabeto: "Eu acho que foi o cigarro, eu fumei 30 anos mais ou menos, quando apareceu já fazia 2 anos que eu tinha deixado de fumar". Mariana também relaciona o seu câncer com o uso do cachimbo e cigarro, percebeu que logo que fumava apresentava uma irritação na garganta e a partir daí resolveu parar de fumar. 0 tabagismo, citado em suas falas como forma de alívio da dor, distração, divertimento, alívio da fome, é testemunho da vivência da vulnerabilidade social desses sujeitos que decorre da pobreza, privação, e/ou fragilização de vínculos afetivo-relacionais e de pertencimento social.

nos contatos sociais, isolamento, ausência de prazer, depressão são algumas das seqüelas que passaram a permear a vida desses sujeitos.

Todos, de uma forma ou de outra, foram envolvidos pelo hábito de fumar. Muitos influenciados pela própria família, pela cultura local e, com certeza, também pelo gigantesco trabalho da mídia. Porém a imagem, tão lisonjeira, sugerida pela publicidade, passou longe da realidade desses sujeitos. Trabalhadores da roça, sofridos, com fome, vestidos com remendos, usando, muitas vezes, o fumo para passar a fome, excluídos da sociedade, essa é a imagem deles. 0 reflexo desse hábito consta nas suas histórias de vida como algo tenebroso, que muda o rumo de suas existências.

Observa-se a necessidade de se investir na prevenção do câncer oral, uma vez que representa uma patologia com taxas significativas de prevalência e incidência, bem como expressiva mortalidade. 0 câncer oral constitui-se em um problema de saúde pública, no entanto inexistem políticas públicas de saúde que contemplem essa realidade. 


\section{Nota}

Roxane Alencar realizou o trabalho de campo, e a redação e a revisão final foram realizados por ambos os autores.

\section{Referências}

1. Goffman E. Estigma: notas sobre a manipulação da identidade deteriorada. Rio de Janeiro (RJ): Livros Técnicos e Científicos; 1988.

2. Costa Neto SB, Araujo T, Curado MP. 0 coping como variável relevante na qualidade de vida de pessoas mutiladas: com um enfoque à pessoa atingida pelo câncer de cabeça e pescoço. In: Kowalski LP, Dib MK, Ikeda MK, Adde C, organizadores. Prevenção, diagnóstico e tratamento do câncer bucal. São Paulo(SP): Frôntis; 1999. p. 546-92.

3. Kowalski IS, Souza CP. Social representations of relatives and patients with oral and oropharyngeal squamous carcinoma on the prevention and diagnosis of cancer. Acta Oncol Bras 2001; 21(1): 206-10.

4. Amar A, Rapoport A, Franzi SA, Bisordi C, Lehn CN. Qualidade de vida e prognóstico nos carcinomas epidermóides de cabeça e pescoço. Rev Bras Otorrinolaringol 2002; 68(400-43).

5. Bertolli Filho $C$. Representações sociais do câncer e dos cancerosos em São Paulo: 1900-1950. Salusvita 2002; 21: 83-116.
6. Pineau G, Le Grand J. Les histoires de vie. Paris(FR): PUF; 1996.

7. Lainé A. Faire de sa vie une historie: théories et pratiques de l'historie de vie em formation. Paris(FR): Collection Sociologie et Clinique; 1998.

8. Sousa LB, Barroso MGT. Pesquisa etnográfica: evolução e contribuição para enfermagem. Esc Anna Nery Rev Enferm 2008; 12(1): 150-55.

9. Geanellos R. Exploring Ricoeur's hermeneutic theory of interpretation as a method of analysing research texts. Nurs Inquiry 2000; 7: 112 -19 .

10. Queiroz MIP. de. Relatos orais: do "indizível" ao "dizível". Ciência Cultura 1987; 39(3): 272-86.

11. Sperber D. La contagion des idées: théorie naturaliste de la culture. Paris(FR): Ed Odile Jacob; 1996.

12. Cavalcante J. Cigarro, o veneno completo: uma análise química dos venenos do cigarro. Fortaleza (CE): INESP; 2000. 